\title{
UOT 541.13
}

\section{TIOSULFAT IOONLARININ MOLIBBDEN ELEKTRODDA ELEKTROREDUKSIYYA PROSESININ TODQIQQI}

\author{
S.F.Cəfərova ${ }^{2}$, V.A.Məcidzadə ${ }^{1}$, A.Ş. Oliyev $^{1}$ \\ ${ }^{1}$ AMEA akad. M.Nağgyev adına Kataliz və Qeyri-üzvi Kimya İnstitutu \\ AZ 1143,Bakl, H.Cavid pr., 113, e-mail:chim.prob.tur@rambler.ru \\ ${ }^{2}$ AMEA akad. H.Abdullayev adina Fizika Institutu \\ AZ 1143, Bakl,H.Cavid pr., 133, e-mail: azhep@ physics.ab.az
}

\begin{abstract}
Taqdim olunan iş Mo elektrodu üzarindo tiosulfat ionlarının katodda reduksiya prosesinin kinetika va mexanizminin aydınlaşdırılmasına hasr edilmişdir. Müəyyən edilmişdir ki, bu proses elektrokimyavi polyarizasiyası ila müşayiat olunur. Polyarizasiyanın tabiati müəyyənlaşdirildikdən sonra bir sira faktorların Mo elektrodu üzərində tiosulfat ionlarının katodda reduksiya prosesina tasiri tadqiq edilmişdir.

Açar sözlori: tiosulfat ionlarl, Mo elektrod, polyarıasiya, elektroreduksiya
\end{abstract}

GİRIŞ

\begin{abstract}
Molibden sulfidin fiziki, kimyəvi tədqiqatçılar tərəfindən tədqiq edilmiş̧ir [1, xassələri onun texnikanın müxtəlif 10]. Lakin bu tədqiqatlar xaotik xarakterli sahələrində, o cümlədən yüksək temperatura davamlı özüyağlayıcı kompozit material, neftkimya sənayesində neftin kükürdsüzləşdirilməsində katalizator, fotoelektrokimyəvi yolla hidrogenin alınması prosesində fotokatalizator kimi geniş tətbiq imkanlarına şərait yaradır. $\mathrm{Bu}$ baxımdan molibden sulfidi tətbiq sahəsindən asılı olaraq müxtəlif üsullarla sintez etmək olar [1-12]. Molibden sulfidin fotokatalizator kimi istifadəsi üçün onun nazik təbəqələr və nanostrukturlar şəklində alınması texnologiyasının işlənib hazırlanması aktual olan məsələlərdən biridir.

$\mathrm{MoS}_{2}$-in nazik təbəqələr və nanostrukturlar şəklində alınması üsüllarından biri və ən perspektivlisi elektrokimyəvi üsuldur. Elektrokimyəvi üsulla sulu məhlullardan $\mathrm{MoS}_{2}$-nin alınması bir sira

olmaqla, hərtərəfli öyrənilməmişdir. $\mathrm{MoS}_{2}$-nin elektrokimyəvi yolla çökdürülməsi prosesinin kinetika və mexanizmini dəqiq araşdırmaq üçün, ilk olaraq birləşmənin tərkibinə daxil olan komponentlərin (Mo və S) ayrı-ayrılıqda sulu məhlullarda çökdürülməsi prosesinin kinetika və mexanizminin tədqiq olunması vacib şərtlərdən biridir. Molibdenin sulu məhlullarında molibdat ionunun katodda reduksiya prosesinin kinetika və mexanizmi bəzi elektrodlar üzərində hərtərəfli tədqiq edilmişdir [13]. Kükürdün sulfit və tiosulfat ionlarından $\mathrm{Ni}$ və $\mathrm{Pt}$ elektrodlarda reduksiya prosesi hərtərəfli aydınlaşdırılmışdır [14-15]. $\mathrm{Bu}$ baximdan təqdim olunan məqalə tiosulfat ionlarının molibden elektrodunda reduksiya prosesinin kinetika və mexanizminin öyrənilməsinə həsr edilmişdir.
\end{abstract}

\section{TӘCRÜBİ HİSSӘ}

Tiosulfat ionlarının molibden elektrodu üzərində reduksiya prosesi aşağıdakı kimi aparılmışdır. Tədqiq edilən elektrolit məhlulu natrium-tiosulfat duzunun $\left(\mathrm{Na}_{2} \mathrm{~S}_{2} \mathrm{O}_{3}\right)$ distillə suyunda həll edilməsilə hazırlanmışdır.

Polyarizasiya əyriləri IVIUMSTAT Electrochemical İnterface potensiostatında çəkilmişdir. $\mathrm{Bu}$ zaman üçelektrodlu elektrolizyordan istifadə edilmişdir. İşçi elektrod kimi səthi $2.04 \cdot 10^{-2} \mathrm{sm}^{2}$ olan Mo elektrodu, müqayisə elektrodu olaraq gümüşxlor $(\mathrm{Ag} / \mathrm{AgCl})$, köməkçi elektrod kimi isə səthi $1.5 \mathrm{sm}^{2}$ olan $\mathrm{Pt}$ lövhədən istifadə olunmuşdur. Tiosulfat ionlarının Mo elektrodu üzərində katodda reduksiya prosesi zamanı elektrolit mohlulunun temperaturu UTU - 4 universal termostatının köməyilə tənzimlənmişdir. 


\section{NӘTİCӘLӘR Və ONLARIN MÜZAKİRӘSİ}

Mo elektrodu üzərində tiosulfat ionlarının katodda reduksiya prosesi adi şəraitdə və temperaturun təsirilə öyrənilmişdir. 298 - 358K intervalında potensiodinamik üsulla çəkılən tsiklik polyarizasiya əyrilərindən görünür ki, temperaturun artması ilə reduksiya prosesinin başlanğıc potensialı müsbət tərəfə sürüşür. $\mathrm{Bu}$ zaman tiosulfat

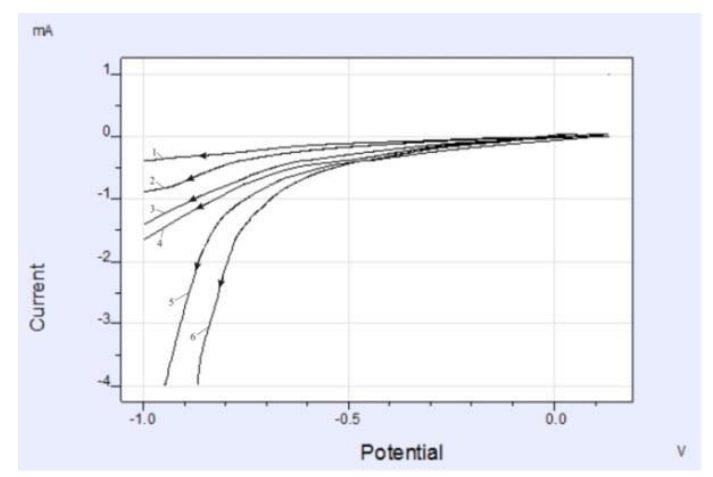

Çəkilən polyarizasiya əyriləri əsasında katodda reduksiya prosesinin effektiv aktivləşmə enerjisi $\left(\mathrm{A}_{\mathrm{ef}}\right)$ hesablanmış və polyarizasiyanın təbiəti müəyyənləşdirilmişdir. Polyarizasiyanın təbiətini təyin etmək üçün şəkil 1-dəki polyarizasiya əyriləri əsasında ionunun katodda reduksiya prosesinə sərf olunan cərəyan da temperaturun artması ilə artır. Yəni temperaturun yüksəlməsi reduksiya prosesini asanlaşdırır. Şəkil 1-dən görünür ki, $298 \mathrm{~K}$ temperaturda tiosulfat ionlarının reduksiyas $1-0.5 \mathrm{~V}, 358 \mathrm{~K}$ temperaturda isə $0.33 \mathrm{~V}$ potensialdan başlayır.

Şəkil 1. Mo elektrodda tiosulfat ionlarının katodda reduksiya polyarizasiya əyriləri. Elektrolit $(\mathrm{mol} / \mathrm{l})$ : $0.5 \mathrm{Na}_{2} \mathrm{~S}_{2} \mathrm{O}_{3}$. Temperatur (K): 1- 298; 2- 318; 3- 328; 4- 338; 5- 348; 6- 358.

$\operatorname{lgi}_{\mathrm{k}}-1 / \mathrm{T}$ asıl11ı̆̆ aktivləşmə enerjisi hesablanmışdır. $A_{\text {eff }}-E$ asılı1ığından göründüyü kimi tiosulfat ionlarının Mo elektrodu üzərində reduksiya prosesi elektrokimyəvi polyarizasiya ilə müşayiət olunur ( $\left.\mathrm{A}_{\mathrm{eff}}=12.5-13.8 \mathrm{kkal} / \mathrm{mol}\right)$.
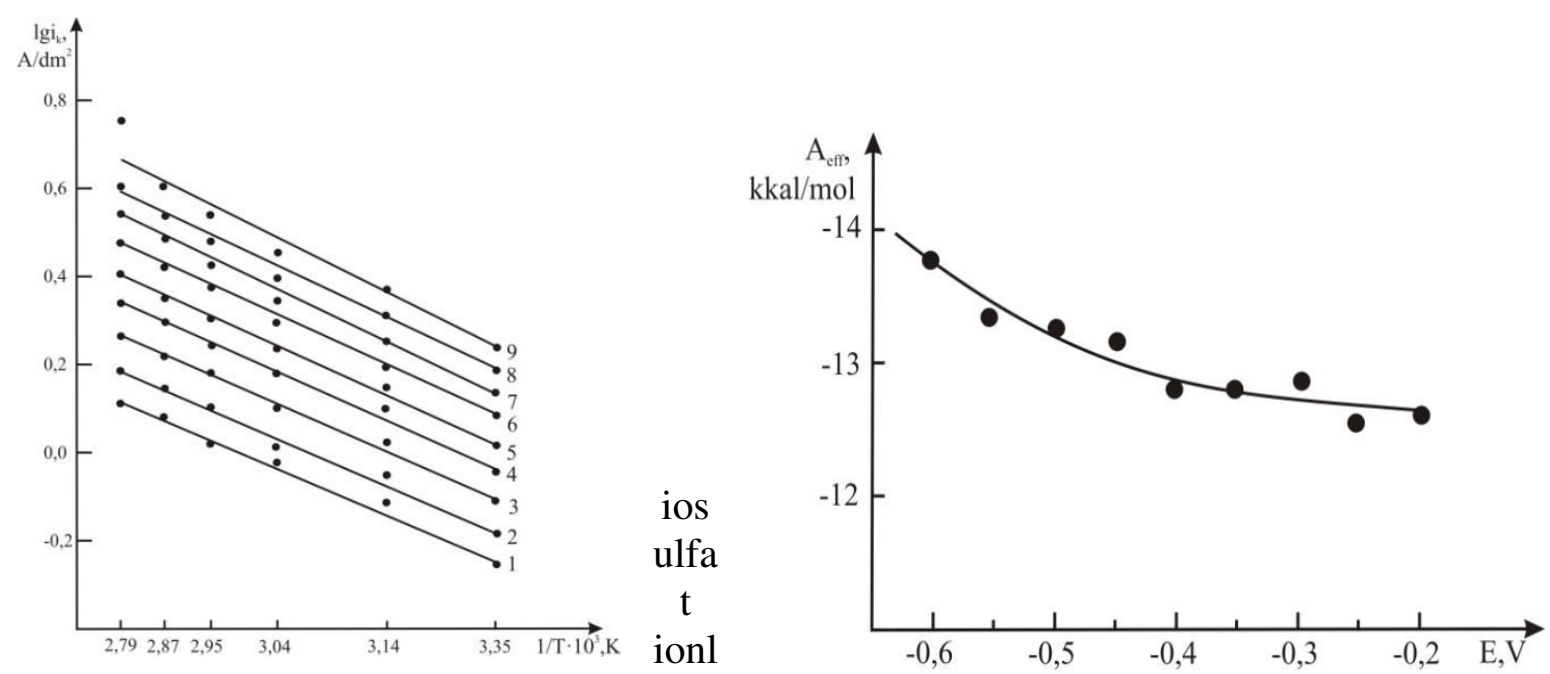

arının Mo elektrodu üzərində katodda olaraa. elektrolitdə bu ionların qatılığının reduksiya prosesinin kinetika və mexan Şəkil 2. $\operatorname{lgi}_{\mathrm{k}}-1 / \mathrm{T}$ asıll1ığı. 1- (-0.2)V, üçün təcrübələr aydınlaşdırıldıqdan sonra bu prosesə bir $2-(-0.25) \mathrm{V}, 3-(-0.3) \mathrm{V}, 4-(0.35) \mathrm{V}, \quad \mathrm{q}$ intervalında faktorların təsiri tədqiq edilmişdir.

5- $(-0.4) \mathrm{V}, 6-(-0.45) \mathrm{V}, 7-(0.5) \mathrm{V}$, $8-(0.55) \mathrm{V}, 9-(-0.6) \mathrm{V}$ 


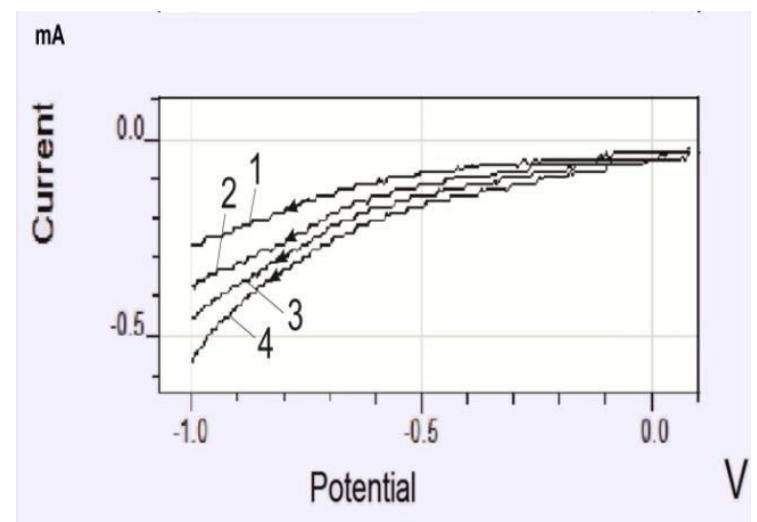

Şəkil 4 - dəki tsiklik polyarizasiya əyrilərindən görünür ki, Mo elektrodu üzərində tiosulfat ionlarının qatılığının $0.1 \mathrm{~mol} / \mathrm{l}$-dən $0.5 \mathrm{~mol} / \mathrm{l}-ə$ qədər artması ilə çökmə potensialı qanunauyğun olaraq daha müsbət tərəfə sürüşür. Qanunauyğunluq həmçinin elektrolitdə tiosulfat ionlarının qatılığının artması ilə cərəyan sıxlığının qiymətinin də artması ilə müşayət olunur. Tiosulfat ionunun hər bir qatılığı üçün çəkilən polyarizasiya

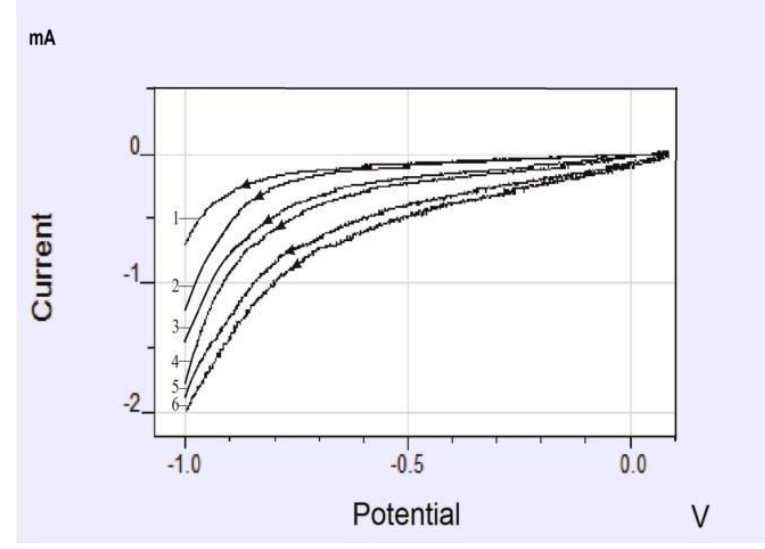

Potensialın dəyişmə sürətinin təsiri $0.005-0.5 \mathrm{~V} / \mathrm{s}$ intervalda öyrənilmişdir (şəkil 5). Şəkildən göründüyü kimi, potensialın dəyişmə sürətinin artması ilə tiosulfat ionlarının Mo elektrodu üzərində katodda reduksiya prosesi daha müsbət potensialda baş verir.
Şəkil 4. Mo elektrodda tiosulfat ionlarının katodda reduksiya prosesinə tiosulfat ionlarının qatılığının təsiri: $\mathrm{Na}_{2} \mathrm{~S}_{2} \mathrm{O}_{3}$ (mol/l): 1- 0.1; 2- 0.2; 3- 0.3; 4- 0.5, $\mathrm{T}=298 \mathrm{~K}$.

əyrilərində reduksiya prosesi $-0.14 \mathrm{~V}$ potensialdan başlayır . Bu zaman reduksiya prosesinə sərf olunan cərəyan $0.1 \mathrm{~mol} / 1$ qatıliq üçün şəkildəki 1-ci əyriyə əsasən $-2.68 \cdot 10^{-4}$ $\mathrm{A}, 0.5 \mathrm{~mol} / \mathrm{l}$ qatılıq üçün isə 4-cü əyriyə isə əsasən $-5.56 \cdot 10^{-4}$ A təşkil edir. Bu da elektrolitdə tiosulfat ionlarının qatılığının artması ilə katodda reduksiya prosesinin sürətlənməsini göstərir.

Şəkil 5. Mo elektrodda tiosulfat ionlarının katodda reduksiya prosesinə potensialın dəyişmə sürətinin təsiri. Elektrolit (mol/l): $0.5 \quad \mathrm{Na}_{2} \mathrm{~S}_{2} \mathrm{O}_{3} . \mathrm{E}_{\mathrm{v}}(\mathrm{V} / \mathrm{s}): 1-0.005 ; 2-$ 0.01 ; 3- 0.05; 4- 0.08; 5- 0.3, 6- 0.5, T= $298 \mathrm{~K}$.

Aparılan bütün tədqiqatlardan belə nəticəyə gəlmək olar ki, Mo elektrodu üzərində tiosulfat ionlarının reduksiyası bu ionların qatılıqlarının və potensialın dəyişmə sürətinin yüksək qiymətlərində daha əlverişlidir. 


\title{
REFERENCES
}

1. Ghosh S.K., Srivastava C., Nath S., Celis J.P. Simple Formation of Nanostructured Molybdenum Disulfide Thin Films by Electrodeposition. Int. J. of Electrochemistry, 2013, p. 1-7.

2. Mahmud El-Roubi, A.Sh.Aliyev, Ch.A.Hasanov, M.N.Mamedov. Electrodeposition of cadmium sulphide. Kimya Problemleri. 2012, № 2, p. 194-206, İSSN 2221-8688.(In Azerbaijan).

3. Radisavljevic B., Radenovic A., Brivio J., Giacometti V., Kis A. Single-layer $\mathrm{MoS}_{2}$ transistors. Nat.Nanotechnol. 2011, 6, p. 147-150.

4. Zhou K.G., Mao N.N., Wang H.X., Peng Y., Zhang H.L. A mixed-solvent strategy for efficient exfoliation of inorganic graphene analogues. Angew. Chem.Int. Ed. 50 2011, p. 10839-10840.

5. Li Y., Wang H., Xie L, Liang Y., Hong G., Dai H. $\mathrm{MoS}_{2}$ Nanoparticles Grown on Graphene: An Advanced Catalyst for the Hydrogen Evolution Reaction. J. Am. Chem. Soc. 2011, 133, p. 7296-7299.

6. C. Altavilla, M. Sarno, P. Ciambelli "A Novel Wet Chemistry Approach for the Synthesis of Hybrid 2D Free-Floating Single or Multilayer Nanosheets of $\mathrm{MS}_{2} @$ oleylamine (M=Mo, W)" Chem. Mater. 23, 2011, p.3879-3883.

7. S. Helveg, J.V. Lauritsen, E. Lægsgaard, I. Stensgaard, J.K. Nørskov,B.S. Clausen, H. Topsøe, F. Besenbacher "Atomic-scale structure of single-layer MoS2 nanoclusters" Phys. Rev. Lett. 84, 2000, p. 951-954.

8. Lauritsen J.V., Kibsgaard J., Helveg S., Topsoe H., Clausen B.S., Lagsgaard E., Besenbacher F. Synthesis and Transfer of
Single-Layer Transition Metal Disulfides on Diverse Surfaces. Nat. Nanotechnol. 2007, 2, p. 53-58.

9. Peng Y., Meng Z., Zhong C., Lu J., Yu W., Jia Y., Qian Y. Synthesis of Large-Area $\mathrm{MoS}_{2}$ Atomic Layers with Chemical Vapor Deposition. Chem. Lett. , 2001, 30, p. 772-773.

10. Balendhran S., Ou J.Z., Bhaskaran M., Sriram S., Ippolito S., Vasic Z., Kats E., Bhargava S., Zhuiykov S., Kalantarzadeh K. Atomically thin layers of $\mathrm{MoS}_{2}$ via a two step thermal evaporation-exfoliation method. Nanoscale. 2012, 4, p. 461-466.

11. Lee Y.H., Zhang X.Q., Zhang W. et al. Synthesis of Large-Area MoS2 Atomic Layers with Chemical Vapor Deposition. Adv. Mater. 2012, 24, p. 2320-2325.

12. Samira Fikret Cafarova, Akif Shikhan Aliyev, Mahmoud Elrouby, N.Sh.Soltanova, Dilgam Babir Tagiyev. Studying the electrochemical deposition process of molybdenum from aqueous solution of molybdate ions. J. Electrochem. Sci. Eng. 2015. 5(4), p. 231-235.

13. Akif Shikhan Aliyev, Mahmoud Elrouby, Samira Fikret Cafarova. Electrochemical syntesis of molybdenum sulfide semiconductor. Materials Science in Semiconductor Processing. 2015, 32, p. 31-39.

14. Akif Shikhan Aliyev, Mahmoud Elrouby, Abbasov M.T., Suleymanov A.S. Electrochemical Reduction Studies on the Behavior of Thiosulfate on Multi Walled Carbon Nano Tubes Paste Electrode. Nanoscience and Nanotechnology: An International Journal. 2013, 3(3), p. 6064.

\section{RESEARCH INTO THE PROCESS OF ELECTROCHEMICAL REDUCTION OF THIOSULFATE IONS ON MOLYBDENUM ELECTRODE}

\author{
S.F.Jafarova ${ }^{2}$, V.A.Majidzade ${ }^{1}$, A.Sh.Aliyev ${ }^{1}$ \\ ${ }^{1}$ Acad. M.Nagiyev Institute of Catalysis and Inorganic Chemistry \\ chim.prob.tur@rambler.ru \\ ${ }^{2}$ Acad. H.Abdullayev Institute of Physics \\ 133, H. Javid Ave., AZ 1143 Baku,; e-mail: azhep@ physics.ab.az
}


The paper deals with research into cathode reduction of thiosulfate ions on Mo electrode. Studies have been carried out in potentiometric regime at 298-358K temperature intervals. It revealed that rise in temperature facilitates the cathode process. The effective activation process energy $\left(A_{e f}\right)$ has been calculated and the nature of polarization identified on the basis of polarization curves. It found that this process is limited by electrochemical polarization. Also, the impact of concentration of thiosulfate ions (0.1-0.5 M) and development of potential (0.005$0.5 \mathrm{~V} / \mathrm{s}$ ) on cathode process of the reduction of thiosulfate on Mo -electrode has also been studied. It established that reduction of thiosulfate ions on the Mo electrode has to be carried out at high values of both factors.

Keyword: thiosulfate ions, molybdenum electrode, polarization, electrochemical reduction

\title{
ИССЛЕДОВАНИЕ ПРОЦЕССА ЭЛЕКТРОХИМИЧЕСКОГО ВОССТАНОВЛЕНИЯ ТИОСУЛЬФАТ-ИОНОВ НА МОЛИБДЕНОВОМ ЭЛЕКТРОДЕ
}

\author{
С.Ф.Джкафарова ${ }^{2}$ В.А.Меджидзаде ${ }^{1}$, А.Н.Алиев ${ }^{1}$ \\ ${ }^{1}$ Институт Катализа и Неорганической Химии им. акад. М. Нагиева \\ Национальной АН Азербайджана \\ AZ 1143 Баку, пр.Г.Джавида, 113; e-mail:chim.prob.tur@rambler.ru \\ ${ }^{2}$ Институт Физики им. акад. Г.Абдуллаева Наџиональной АН Азербайджана \\ AZ 1143 Баку, пр.Г.Джавида, 133; e-mail: azhep@ physics.ab.az
}

Представленная работа посвящена катодному восстановлению тиосульфат-ионов на поверхности молибденового электрода. Исследования проводились в потециодинамическом режиме в интервале температур 298-358 K. Установлено, что повышение температуры значительно облегчает катодный прочесс. Из полученных поляризачионных кривых была рассчитана эффективная энергия активации процесса $\left(A_{\ni \phi}\right)$ и определена природа поляризации. Установлено, что процесс лимитируется электрохимической поляризацией. Было такэе исследовано влияние концентрации тиосульфат-ионов (0.1-0.5 М) и развертки потенциала (0.005 - 0.5 В/сек) на катодный процесс восстановления тиосульфат ионов на молибденовом электроде. Определено, что восстановление тиосульфат ионов на молибденовом электроде необходимо проводить при высоких значениях обоих этих факторов.

Ключевые слова: тиосульфат ионы, молибденовый электрод, поляризаџия, электрохимическое восстановление.

Redaksiyaya daxil olub 26.11.2016. 